\title{
Base Nacional Comum para a Educação Infantil: um tema em debate
}

\section{Early childhood Education National Core Curriculum: a debate}

Zilma de Moraes Ramos de Oliveira é pedagoga e doutora em Psicologia pela Universidade de São Paulo (USP), professora associada (aposentada) da Faculdade de Filosofia, Ciências e Letras de Ribeirão Preto da USP, coordenadora do curso de especialização em Gestão Pedagógica e Formação em Educação Infantil do Instituto Superior de Educação Vera Cruz (ISE Vera Cruz) e assessora de redes públicas de ensino na área de Educação Infantil.

Contato: zilmaoliveira@uol.com.br

\section{Resumo}

0 artigo relata e problematiza questões envolvidas na definição de uma Base Nacional Comum no que se refere à Educação Infantil. 0 processo de construção dessa base é delineado e é exposta a versão preliminar da mesma no que se refere aos direitos de aprendizagens e à organização curricular em campos de experiências.

Palavras-chave: Educação Infantil, currículo, Base Nacional Comum Curricular

\section{Abstract}

The article presents some questions involved in the definition of a National Core Curriculum for Early childhood Education and the construction of the core itself. It also contains a preliminary version of this definition concerning child's learning rights and the curriculum organization in the fields of experiences.

Keywords: Early Childhood Education, curriculum, National Core Curriculum 
Desde a Constituição Federal de 1988 a Educação Infantil integra a Educação Básica e defende que as crianças pequenas têm direito a conviver e aprender com outras crianças e adultos fora do âmbito familiar em contextos educativos como a creche e a pré-escola. 0 muito do que já se sabe sobre os processos de aprendizagem e desenvolvimento de crianças de até 5 anos de idade deve ser considerado para organizar vivências na Educação Infantil que assegurem às crianças seus direitos de aprendizagem.

A relação com a Educação Básica coloca ao conjunto dos professores e demais profissionais da Educação Infantil a necessidade de refletir sobre a organização curricular dessa etapa de ensino que defenda sua especificidade, mas seja forma integrada aos demais níveis de ensino, buscando superar fragmentações no processo educativo. Cada vez mais na área se considera que o currículo:

a) abrange a reelaboração de conhecimentos socialmente significativos e contextualmente relevantes para as novas gerações em uma sociedade complexa;

b) efetiva-se nos modos de organizar e estruturar as práticas escolares cotidianas;

c) parte da identificação de conhecimentos socialmente significativos e contextualmente relevantes para as crianças, na escuta atenta do que elas expressam.

d) necessita ter atenção às singularidades dos educandos e suas diversidades culturais, sociais, étnicas, promovendo experiências que Ihes ofereçam a possibilidade de perceber um mundo diversificado, múltiplo e construir um sentido de si no processo.

e) requer o estabelecimento de uma relação de parceria com as famílias, constituindo um ambiente norteado por um projeto pedagógico significativo para a comunidade, que complementa e promove experiências de aprendizagem dos educandos.

f) é fruto do trabalho coletivo e a reflexão de cada professor e do conjunto de profissionais da instituição educacional na efetivação de seu projeto pedagógico.

Essa perspectiva está ligada à questão do currículo, ainda muito nova na área, o que tem gerado intenso debate entre os educadores e outros profissionais envolvidos com aquele nível educacional. 
Presentemente o debate sobre o currículo na Educação Infantil convive com as determinações legais de elaboração de uma Base Nacional Comum para a Educação Básica (Resolução CNE/ CEB $n^{\circ} 4 / 10$ ) que constitua uma perspectiva de unidade para todos os níveis de ensino como forma de garantir um caminho de integração curricular. A Base Nacional Comum em cada nível de ensino deve ser composta por uma parte comum e outra, chamada de parte diversificada, que evidencie tanto os conhecimentos regionais, locais, como também aqueles que são específicos para determinado momento do ciclo da vida, sendo que as duas partes devem ser compreendidas como organicamente articuladas, planejadas e geridas. Ela deve apontar os conhecimentos e as experiências que orientam as escolhas para a produção de currículos nos sistemas e nas escolas.

O objetivo de uma Base Nacional Comum Curricular Nacional não é o de restringir ou desenhar a totalidade do currículo da escola, mas sim subsidiar alguns aspectos que devem compor a Proposta Pedagógica da escola, sendo que o currículo como um todo será construído pela comunidade educacional de cada órgão federado e de cada unidade educativa em particular. Nesse processo, a educação infantil precisa discutir vivamente seus objetivos e atividades com as famílias e a comunidade.

\section{A Base Nacional Comum para a Educação Infantil: um movimento em ação}

0 ponto básico na discussão de uma base curricular para a Educação Infantil é a especificidade dessa etapa educacional na organização de situações educativas potencialmente geradoras de aprendizagem, desenvolvimento e socialização.

As atuais Diretrizes Curriculares Nacionais da Educação Infantil (DCNEI - Resolução CNE/CEB nº. 05/09, artigo $4^{\circ}$ ) são o documento legal que orientou a definição da BNC da Educação Infantil. Ele define a criança como "um sujeito histórico e de direitos que brinca, imagina, fantasia, deseja, aprende, observa, experimenta, narra, questiona e constrói sentidos sobre a natureza e a sociedade, produzindo cultura".

Continua o documento das DCNEI: "As crianças reagem ao mundo fortemente guiadas por suas emoções, buscam conhecer diferentes pessoas, adultos e crianças, adquirem maior autonomia para agir nas práticas cotidianas que envolvem as tarefas de 
alimentação, higiene, na integração do educar e cuidar. Nesse período etário, mais do que em qualquer outro, as interações e as brincadeiras, em especial a de faz-de-conta, são os principais mediadores das aprendizagens da criança e se fazem presente em todo o tipo de situação: nas explorações de objetos e elementos da natureza, no reconhecimento dos comportamentos dos parceiros, no acompanhamento de uma apresentação musical ou de uma história sendo contada".

Esse potencial aponta para o direito de as crianças, desde seu nascimento até 6 anos de idade, cultivar sua curiosidade e ter acesso a processos de apropriação, renovação e articulação de saberes e conhecimentos, como requisito para a formação humana, para a participação social e para a cidadania. Além disso, devem ter assegurado seu direito à proteção, à saúde, à liberdade, à confiança, ao respeito, à dignidade, à cultura, às artes, à brincadeira, à convivência e à interação com outras crianças.

$\mathrm{Na}$ Educação Infantil realizada em creches e pré-escolas, o currículo é concebido como "conjunto de práticas que buscam articular as experiências e os saberes das crianças com os conhecimentos que fazem parte do patrimônio cultural, artístico, ambiental, científico e tecnológico". Ele se distingue da ideia de currículo como uma lista de conteúdos simplificados e/ou matérias ou disciplinas escolares convencionais e salienta a responsabilidade dos professores em selecionar do patrimônio de conhecimentos sistematizados aqueles que estejam contextualizados nas realidades das escolas e que sejam os mais significativos para as crianças com seus modos próprios de elaborar saberes e interagir com novos conhecimentos. Nesse sentido, o trabalho do professor junto às crianças reconhece tanto a intencionalidade da prática pedagógica na organização dos espaços, tempos, materiais, relações sociais, na seleção de experiências de aprendizagem, quanto o protagonismo de cada criança nessa organização e seleção, em vez de ser um processo de ensino centrado em decisões apenas dos adultos.

Considera-se que a construção de conhecimentos pelas crianças nas unidades de Educação Infantil, localizadas em zonas urbanas e no campo, efetiva-se na participação delas em diferentes práticas culturais nas quais interagem com parceiros adultos e companheiros de idade e levantam interrogações relativas ao mundo físico e social que as circunda. Para elas o direito de aprender não se impõe como uma tarefa exterior, mas responde a um forte desejo de satisfazer sua curiosidade diante do mundo e de seus pares. Para tanto as especificidades e os interesses singulares 
e coletivos das crianças devem ser considerados norteadores no planejamento do currículo, e cada criança deve ser vista como uma pessoa inteira na qual os aspectos motores, afetivos, cognitivos e linguísticos integram-se, estabelecem conflitos e permanecem, embora em constante mudança. Segundo as DCNEI, em qualquer atividade geradora de possíveis aprendizagens proposta pelos professores às crianças, devem ser abolidos os procedimentos que não reconhecem a atividade criadora e o protagonismo infantil e que promovam apenas atividades mecânicas e não significativas para as crianças.

As DCNEl (Resolução CNE/CEB n 0 05/09 artigo 9²), em vez de proporem a organização do currículo em disciplinas, áreas de desenvolvimento, campos de conhecimento, dentre outras, em consonância com linhas atuais de pensamento sobre o currículo, apontaram a necessidade de organização de experiências de socialização, aprendizagem e desenvolvimento, considerando sempre o caráter vivencial, interdisciplinar, mobilizador da autonomia infantil que tais experiências devem assegurar. Elas abrangem dois elementos: o caráter prático-reflexivo que devem assumir as práticas pedagógicas propostas pelos professores às crianças e a valorização do sentido pessoal que cada criança empresta às vivências e aos conhecimentos nelas construídos.

As experiências selecionadas, preparadas, efetivadas com as crianças e avaliadas quanto a seu papel de mediação da aprendizagem constituem situações concretas em que as crianças ag’em, emocionam-se, avaliam e propõem soluções, em um projeto pedagógico articulado com suas competências e histórias pessoais de significação e com as diferentes linguagens que se fazem presentes hoje.

As experiências cotidianamente estruturadas nas unidades de Educação Infantil a partir dos eixos interações e brincadeiras devem possibilitar a todas as crianças, conforme as DCNEI (artigo $9^{\circ}$ da Resolução CNE/CEB n ${ }^{\circ}$ 05/09):

- o conhecimento de si e do mundo por meio da ampliação de experiências sensoriais, expressivas, corporais que possibilitem movimentação ampla, expressão da individualidade e respeito pelos ritmos e desejos da criança;

- a imersão delas em diferentes linguagens e o progressivo domínio por elas de vários gêneros e formas de expressão: gestual, verbal, plástica, dramática e musical; 
- experiências de narrativas, de apreciação e interação com a linguagem oral e escrita, e convívio com diferentes suportes e gêneros textuais orais e escritos;

- a recriação, em contextos significativos para elas, de relações quantitativas, medidas, formas e orientações espaço-temporais;

- ampliar sua confiança e participação nas atividades individuais e coletivas;

- $\quad$ situações de aprendizagem mediadas pelos educadores para elas desenvolverem sua autonomia nas ações de cuidado pessoal, autoorganização, saúde e bem-estar;

- vivências éticas e estéticas com outras crianças e grupos culturais que alarguem seus padrões de referência e de identidades no diálogo e conhecimento da diversidade;

- a curiosidade, a exploração, o encantamento, o questionamento, a indagação e o conhecimento em relação ao mundo físico e social, ao tempo e à natureza;

- o relacionamento e a interação delas com diversificadas manifestações de música, artes plásticas e gráficas, cinema, fotografia, dança, teatro, poesia e literatura;

- a interação, o cuidado, a preservação e o conhecimento por elas da biodiversidade e da sustentabilidade da vida na Terra, assim como o não desperdício dos recursos naturais;

- a interação e o conhecimento de manifestações e tradições culturais brasileiras;

- a utilização de gravadores, projetores, computadores, máquinas fotográficas e outros recursos tecnológicos e midiáticos.

Os eixos norteadores do currículo na Educação Infantil são as interações, reconhecendo o valor das diversas relações nas quais a criança se envolve no aprendizado dos mais diferentes aspectos, e a ludicidade, como ação a ser priorizada nesse momento de vida das crianças, dado que, ao brincar, as crianças interagem e constroem cenas a partir dos materiais disponíveis, de memórias de situações ou de histórias, de canções, de rituais, trabalhando a linguagem verbal e corporal, os papéis sociais e as regras de vida social (Deliberação CNE/CEB n²0/09). 
Cabe ao professor criar oportunidades, a partir de sua observação, para que as crianças, no processo de elaborar sentidos pessoais, se apropriem de elementos significativos de sua cultura como elaborações dinâmicas e provisórias.

Nesse processo é necessário reconhecer dois pontos. 0 primeiro diz respeito ao modo como as crianças pequenas se relacionam com o mundo, a especificidade dos recursos que utilizam, tais como a corporeidade, a linguagem, a emoção. Entender essa forma relacional afetiva, muito ligada à vivência pessoal, é crucial no trabalho pedagógico na Educação Infantil.

O segundo ponto chama a atenção para o reconhecimento de que os discursos e as práticas cotidianas vivenciados nas instituições educacionais influem nos modos como as crianças e adultos vivem, aprendem e são subjetivadas/os, já desde o nascimento, com fortes impactos para sua própria imagem e para o modo como se relacionam com os demais.

Como as diversas possibilidades de experiências que as crianças podem usufruir na unidade de Educação Infantil e citadas no parecer acima não ocorrem de modo isolado, ou fragmentadas, mas são promovidas por um conjunto de práticas que articulam os saberes e fazeres das crianças com os conhecimentos já sistematizados pela humanidade, daí a proposta do arranjo curricular para a Educação Infantil se dar em Campos de Experiências.

Os Campos de Experiências colocam, no centro do projeto educativo, as interações, as brincadeiras, de onde emergem as observações, os questionamentos, as investigações e outras ações das crianças articuladas com as proposições trazidas pelos/as professores/as. Cada um deles oferece às crianças a oportunidade de interagir com pessoas, objetos, situações e atribuir um sentido pessoal a eles. Os conhecimentos aí elaborados, reconhecidos pelo professor como fruto das experiências das crianças, são por ele mediados para qualificar e aprofundar as aprendizagens feitas.

Na perspectiva da integração entre a Educação Infantil e os anos iniciais do Ensino Fundamental, os campos de experiências - organização interdisciplinar, por excelência - fundamentam importantes processos das crianças que terão continuidade e progressão nas demais etapas da Educação Básica. 


\section{A Base Nacional Comum da Educação Básica em debate}

Até o final do ano de 2015, uma versão preliminar da BNC, incluindo o que se refere à Educação Infantil, está disponível para consulta e manifestação pública no site do MEC. Dado que se espera que o texto receba contribuições no sentido de seu aprimoramento e adequação às culturas escolares dos diversos pontos do país, serão apresentados aqui os objetivos gerais enquanto direitos de aprendizagem das crianças de zero a 6 anos e os campos de experiência propostos para a organização curricular.

Considerando as formas pelas quais meninos e meninas aprendem, ou seja, convivendo, brincando, participando, explorando, expressando-se/comunicando e conhecendo-se, seis grandes direitos de aprendizagem devem ser garantidos na Educação Infantil. São eles:

- CONVIVER democraticamente com outras crianças e adultos, com eles interagir utilizando diferentes linguagens, e ampliar o conhecimento e o respeito em relação à natureza, à cultura e às singularidades e diferenças entre as pessoas.

- BRINCAR cotidianamente de diversas formas e com diferentes parceiros, interagindo com as culturas infantis, construindo conhecimentos e desenvolvendo sua imaginação, sua criatividade, suas capacidades emocionais, motoras, cognitivas e relacionais.

- PARTICIPAR, com protagonismo, tanto no planejamento como na realização das atividades recorrentes da vida cotidiana, na escolha das brincadeiras, dos materiais e dos ambientes, desenvolvendo linguagens e elaborando conhecimentos.

- EXPLORAR movimentos, gestos, sons, palavras, histórias, objetos, elementos da natureza e do ambiente urbano e do campo, interagindo com diferentes grupos e ampliando seus saberes e linguagens.

- EXPRESSAR/COMUNICAR por meio de diferentes linguagens, opiniões, sentimentos, desejos, pedidos de ajuda, narrativas de experiências, registro de vivências e de conhecimentos, ao mesmo tempo que aprende a compreender o que os outros lhe comunicam.

- CONHECER-SE e construir sua identidade pessoal e cultural, constituindo uma imagem positiva de si e de seus grupos de pertencimento nas diversas interações e brincadeiras vivenciadas na instituição de Educação Infantil. 
Preservando as especificidades das crianças de até 6 anos, os Campos de Experiências propostos para orientar o trabalho pedagógico em creches e pré-escolas e apresentados na versão preliminar do documento da BNC são:

\section{O EU, O OUTRO E ONÓS \\ CORPO, GESTOS E MOVIMENTOS \\ ESCUTA, FALA, PENSAMENTO E IMAGINAÇÃO \\ TRAÇOS, SONS, CORES E IMAGENS \\ ESPAÇOS, TEMPOS, QUANTIDADES, RELAÇÕES E TRANSFORMAÇÕES}

Esses campos estão sendo debatidos na consulta pública neste segundo semestre de 2015 e após sua apreciação final pelo Conselho Nacional de Educação em 2016 serão apresentados aos educadores e às comunidades com seus objetivos de aprendizagem. 0 importante é desvincular a ideia de campo da de disciplina escolar. Um ou dois campos podem subsidiar o trabalho por certo tempo com uma turma, cujas crianças poderão ainda envolver-se com atividades de exploração de elementos integrantes da parte diversificada do currículo de uma unidade.

Como finaliza o referido texto preliminar da BNC, "cabe ao sistema educacional garantir as condições necessárias ao trabalho pedagógico na Educação Infantil: a organização de espaços que ofereçam às crianças oportunidades de interação, exploração e descobertas; o acesso a materiais diversificados geradores de enredos para as explorações, para as produções e para as brincadeiras infantis e a gestão do tempo, proporcionando uma jornada que lhes dê o tempo necessário para viverem suas experiências cotidianas, valorizando especialmente as oportunidades de interações e brincadeiras. Cabe-Ihe ainda prover subsídios para pensar formas de acompanhamento e avaliação do trabalho com as crianças no que se refere ao que foi aqui exposto". 


\section{REFERÊNCIAS}

BRASIL. Constituição (1988). Constituição da República Federativa do Brasil. Brasília, DF: Senado Federal: Centro Gráfico, 1988. 292 p.

MINISTÉRIO DA EDUCAÇÃO/CONSELHO NACIONAL DE EDUCAÇÃO/CÂMARA DE EDUCAÇÃO BÁSICA. Resolução no 4, de 13 de julho de 2010. Define a Diretrizes Curriculares Nacionais Gerais para a Educação Básica. Diário Oficial, Brasília, DF, 13 jul. 2010.

MINISTÉRIO DA EDUCAÇÃO/CONSELHO NACIONAL DE EDUCAÇÃO/CÂMARA DE EDUCAÇÃO BÁSICA. Resolução no 5, de 17 de dezembro de 2009. Fixa as Diretrizes Curriculares Nacionais para a Educação Infantil. Diário Oficial da União, Brasília, 18 dez. 2009, Seção 1, p. 18.

MINISTÉRIO DA EDUCAÇÃO/CONSELHO NACIONAL DE EDUCAÇÃO/CÂMARA DE EDUCAÇÃO BÁSICA. Parecer no 20, de 9 de dezembro de 2009. Revisa Diretrizes Curriculares Nacionais para a Educação Infantil. Diário Oficial da União, Brasília, 9 dez. 2009, Seção 1, p. 14.

Recebido em: 28/10/2015.

Revisto em: 11/11/2015.

Aceito em: 13/11/2015.

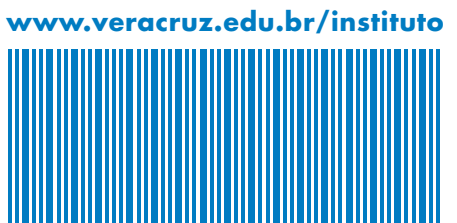

